\title{
A CFD Database for Airfoils and Wings at Post-Stall Angles of Attack
}

\author{
Justin Petrilli, ${ }^{*}$ Ryan Paul ${ }^{\dagger}$ Ashok Gopalarathnam, ${ }^{\ddagger}$ \\ Department of Mechanical and Aerospace Engineering \\ North Carolina State University, Raleigh, NC 27695-7910 \\ and \\ Neal T. Frink ${ }^{\S}$ \\ NASA Langley Research Center, Hampton, Virginia, 23681
}

\begin{abstract}
This paper presents selected results from an ongoing effort to develop an aerodynamic database from Reynolds-Averaged Navier-Stokes (RANS) computational analysis of airfoils and wings at stall and post-stall angles of attack. The data obtained from this effort will be used for validation and refinement of a low-order post-stall prediction method developed at NCSU, and to fill existing gaps in high angle of attack data in the literature. Such data could have potential applications in post-stall flight dynamics, helicopter aerodynamics and wind turbine aerodynamics. An overview of the NASA TetrUSS CFD package used for the RANS computational approach is presented. Detailed results for three airfoils are presented to compare their stall and post-stall behavior. The results for finite wings at stall and post-stall conditions focus on the effects of taper-ratio and sweep angle, with particular attention to whether the sectional flows can be approximated using two-dimensional flow over a stalled airfoil. While this approximation seems reasonable for unswept wings even at post-stall conditions, significant spanwise flow on stalled swept wings preclude the use of two-dimensional data to model sectional flows on swept wings. Thus, further effort is needed in low-order aerodynamic modeling of swept wings at stalled conditions.
\end{abstract}

\section{Nomenclature}

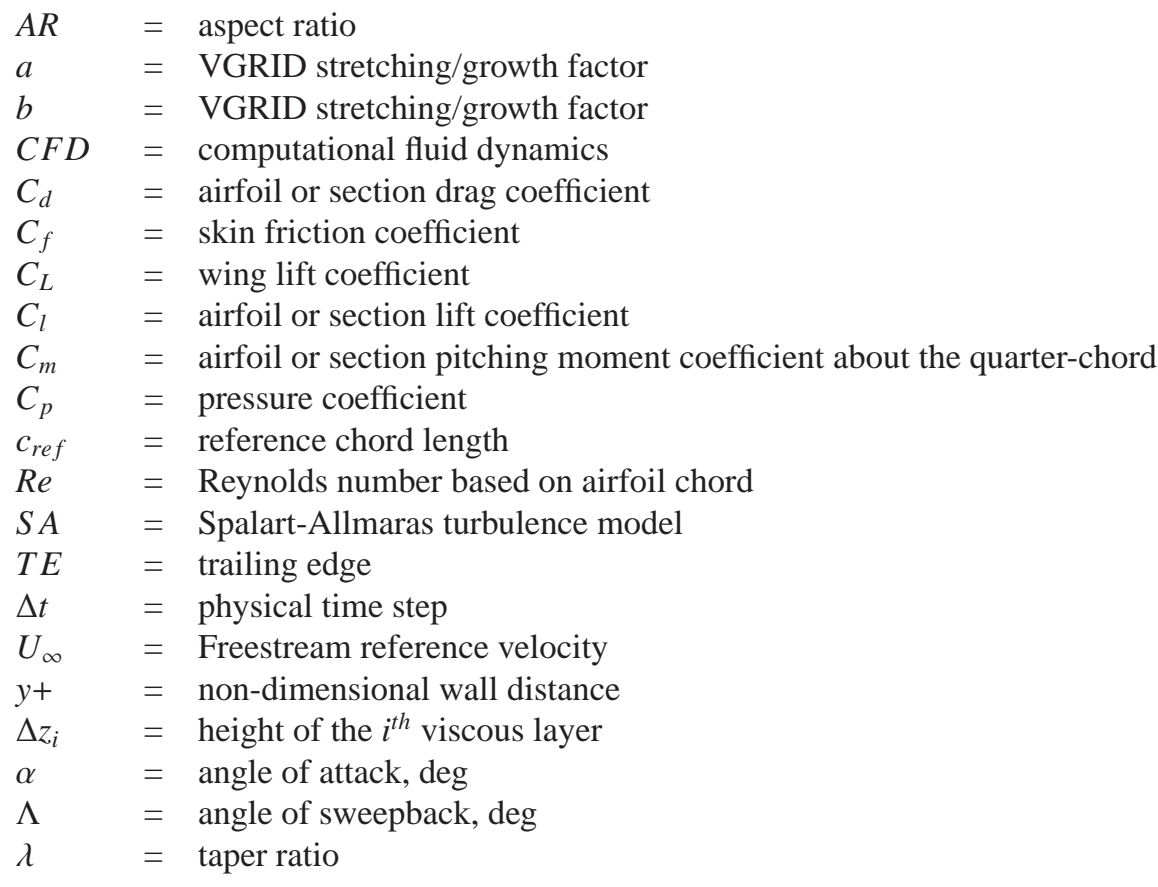

\footnotetext{
*Graduate Research Assistant, Box 7910, jlpetril@ncsu.edu. Student Member, AIAA

${ }^{\dagger}$ Graduate Research Assistant, Box 7910, rcpaul@ncsu.edu. Student Member, AIAA

¥Associate Professor, Box 7910, ashok_g@ncsu.edu, (919) 515-5669. Associate Fellow, AIAA

$\S$ Aerospace Engineer, Configuration Aerodynamics Branch, MS499. Associate Fellow, AIAA
} 


\section{Introduction}

Airfoil lift and moment data in the low angle of attack regime is readily available from a multitude of sources- from Abbott and von Doenhoff [1] and those from the University of Stuttgart [2] and University of Illinois at UrbanaChampaign [3,4,5], to modern computational approaches designed to predict sectional aerodynamic characteristics based on arbitrary input geometry, such as XFOIL [6]. For many applications, data in this linear regime is sufficient. However, fields such as wind turbine aerodynamics, helicopter aerodynamics and post-stall flight dynamics of fixedwing aircraft require data to extend beyond aerodynamic stall. Efforts have been made in the wind turbine community and the helicopter aerodynamics community to extend airfoil data into the post-stall regime. In both wind turbine and helicopter aerodynamics, local blade sections close to the root of the rotor may experience very high angles of attack. Models for airfoil force and moment coefficients at high angle of attack conditions have been developed experimentally [7,8], which has led to researchers proposing empirical models based on flat plate theory [9]. The empirical models developed from experiment require that both the maximum $C_{l}$ and the corresponding $\alpha_{\text {stall }}$ at which this lift coefficient occurs be known reliably before theoretical flat plate data may be fitted to extend the data well into post-stall.

Very little data exists in the literature covering the stall behavior of finite wings, especially that which extends deep into post-stall. Published work in post-stall wing aerodynamics often covers general stall behavior, dependent on factors such as planform, without providing detailed force and moment data beyond initial stall [10]. Some studies propose empirical methods based on theory to extend existing force and moment coefficient data-sets deep into poststall taking into account 3D effects with some correction for aspect ratio [8]. An interesting, purely experimental study, that covers the stall of both a 2D airfoil section and 3D wings of various aspect ratios was performed by Ostowari and Naik in 1985 [11]. The study presented consistent lift coefficient versus angle of attack data for various NACA 44XX series airfoils and 3D rectangular wings with a range of aspect ratios having the same airfoils as cross sections.

A database of post-stall airfoil and wing data, with a similar scope to the Ostowari and Naik study, was desired partly to address this dearth of data in the literature, but primarily to support a local effort within the Applied Aerodynamics Group at North Carolina State University. The ongoing effort involves developing a low-order model of post-stall aerodynamics for finite wings via use of existing linear low-order methods (VLM, Weissinger or LLT) corrected for nonlinear sectional airfoil behavior. Corrections are accomplished via a decambering approach used to mimic the nonlinear aerodynamics caused by flow separation. Details of the development of the low-order method may be found in Ref. [12], with the current status pertaining to its use in real-time simulation of aircraft flight dynamics described in Ref. [13]. In addition to geometry information, the low-order post-stall model requires sectional 2D airfoil data as input for each of the control points. This sectional input data $\left(C_{l}-\alpha, C_{d}-\alpha\right.$, and $C_{m}-\alpha$ curves $)$ defines the convergence criteria for the low-order post-stall calculation for finite wings. Outputs include the total aerodynamic force and moment coefficients and spanwise distributions of these coefficients.

Figure 1 describes the relationship between the low-order method and the higher order Computational Fluid Dynamics (CFD) effort, and how the results from the latter are to be used for initial validation and further refinement of the former. Two dimensional CFD is performed on airfoil sections, and the outputs are used as inputs to the low-order method. The 3D geometries utilizing the same 2D cross section are run in both CFD and the low-order method.The results are then compared on the basis of total force/moments and spanwise force/moment distributions. CFD solutions and accompanying flow visualizations allow for further development and refinement of the low-order method. Comparisons between the low-order method and CFD are beyond the scope of this paper. This paper aims to discuss the methodology used in generating CFD solutions of airfoils and wings in post-stall angles of attack and to present the results in this regime as dependent on geometry and flow conditions.

This paper begins by describing the CFD software package that was chosen to generate consistent flow solutions for airfoils and wings. The methodology developed to effectively use the CFD package is presented next - from generating usable geometry, creating a suitable grid over the computational domain, running the flow-solver, checking solution convergence, and post-processing to extract desired quantities from the outputs. The 2D and 3D results are presented which show effects from geometry, including wing sweep, and flow parameters. Selected results are shown in more detail using flow visualization and/or spanwise local lift coefficient distributions. 


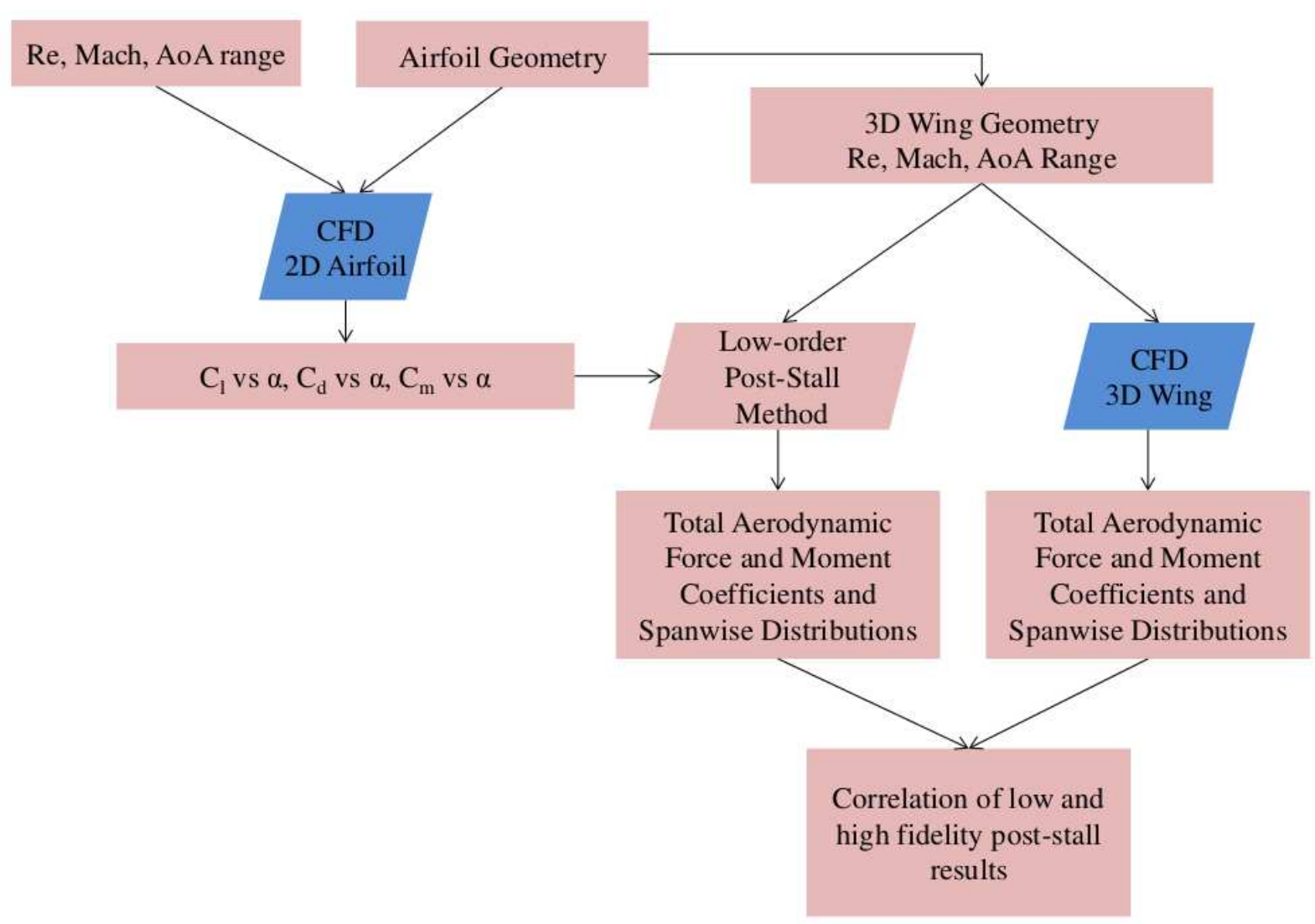

Figure 1: Approach for using CFD for initial validation and further refinement of the low-order method. Blue emphasizes that a consistent grid spacing is used with the 2D and 3D CFD discretizations.

\section{Background: NASA Tetrahedral Unstructured Software System}

The NASA Tetrahedral Unstructured Software System (TetrUSS) [14] is a package of loosely integrated software, developed to allow rapid aerodynamic analysis from simple to complex problems. The system has its origins in 1990 at the NASA Langley Research Center and has won the NASA Software of the Year Award twice. TetrUSS has been used on high priority NASA programs such as Constellation and the new Space Launch System for aerodynamic database generation along with work in the Aviation Safety Program. The component software packages are assembled such that a user follows a systematic process during each application of TetrUSS. There are software packages for preparing geometries for grid generation (GridTool), generating unstructured surface and volume grids (VGRID) and calculating flow solutions (USM3D). Post-processing the solutions with TetrUSS can be done using the included SimpleView software or by easily converting for use with other commercial packages (eg Tecplot, EnSight etc.).

For preparing geometries for grid generation, GridTool is used to generate the necessary VGRID [15] input files. GridTool can read Non-uniform Rational B-Spline (NURBS) curves and surfaces through an Initial Graphics Exchange Specification (IGES) file, as well as PLOT3D point cloud surface definitions. The geometric surfaces are then defined by way of surface patch construction. Each patch has a specified boundary condition such as a viscous or inviscid surface and a family definition for users to group related patches together. Grid spacing parameters are also defined and controlled within GridTool. Sources are placed in three dimensional space by a user in order to control the size and growth rates of the tetrahedral cells. Numerous classes of sources are available to control the grid topography. Nodal sources and line sources are typically used in most cases, while volume sources are available for use in specific cases requiring control over a large volume of the domain. Other parameters defined in GridTool are the viscous layer spacing parameters and the maximum and minimum tetrahedral sizes.

VGRID is the unstructured grid generation tool used in the TetrUSS Package. Viscous layer generation is accomplished via the Advancing Layers Method (ALM) [16]. Tetrahedral cells are generated in an orderly manner, "marching" nodes away from the surface. The size and growth of these cells is controlled by Equation 1. 


$$
\Delta z_{i+1}=\Delta z_{1}\left[1+a(1+b)^{i}\right]^{i}
$$

In this equation, the height of the $i^{\text {th }}$ layer is determined by an initial spacing parameter, $\Delta z_{1}$, and two stretching/growth factors $a$ and $b$. Once the height of the $i^{\text {th }}$ layer reaches the size of the background sources specified by the user in GridTool, no more cells are formed and viscous layer generation is complete. After the viscous layers are generated, VGRID then utilizes the Advancing Front Method (AFM) [17] for the generation of the inviscid portion of the volume grid. VGRID can not always close the grid completely. When this occurs, a slower but more robust auxiliary code called POSTGRID is used to complete the formation of the remaining tetrahedral cells.

The flow solver at the core of the TetrUSS package is USM3D [18]. USM3D is a parallelized, tetrahedral cellcentered, finite volume Reynolds Averaged Navier-Stokes (RANS) flow solver. It computes the finite volume solution at the centroid of each tetrahedral cell and utilizes several upwind schemes to compute inviscid flux quantities across tetrahedral faces. USM3D has numerous turbulence models implemented for use; the Spalart-Allmaras (SA) oneequation model and Menter Shear Stress Transport (SST) two equation model were used in this study. Some additional capabilities that USM3D has implemented are dynamic grid motion and overset grids.

\section{Methodology: Developing the Aerodynamic Database}

The aerodynamic database is desired to have high fidelity flow solutions for a wide variety of 2D airfoils and 3D geometries. Flow solutions would include a large range of angles of attack to encompass pre-stall, stall and post-stall flow regimes. The data gained from these simulations will be vital in assisting the further development and validation of the low-order method mentioned in the introduction as well as to fill gaps in the currently available high angle of attack aerodynamic data for arbitrary geometries. An efficient process to go from a geometry to a converged flow solution was developed and is discussed in the following sub-sections.

\section{A. Geometry Generation}

Traditional Computer Aided Design (CAD) software would be more than adequate for the creation of the desired geometries, however these tools are not geared specifically towards the modeling of wings and airfoils. Understanding this, the recently released parametric modeling tool, Open Vehicle Sketch Pad (OpenVSP) [19], was chosen as the geometry generation tool. A flow chart showing the process of geometry generation can be seen in Figure 2. OpenVSP is a modeling package developed and released by NASA Langley Research Center in Hampton, Virginia. The unique concept that OpenVSP provides is that it allows a user to drag and drop generic aircraft components (such as a wing) into the modeling area, and directly manipulate familiar geometric parameters. Consequently, it is simple to insert a wing, change its root chord, tip chord, span, etc. and view the resulting geometry in real time. Aerodynamic reference quantities can also be automatically calculated for the user. Airfoils cross section generation is also simplified. A user can select any 4 or 5 digit series NACA airfoil or load in a formatted airfoil coordinate file for use on any lifting surface.

The 3D wing and corresponding airfoil for each case to be analyzed were generated in OpenVSP. In order to read the geometry into GridTool, the file must be in the IGES format. Vehicle Sketch Pad does not output IGES files, thus each geometry must be exported as a Rhino3D formatted file. The Rhinoceros NURBS modeling package was used to convert the geometry into the necessary IGES file as well as make small modifications to the geometry. Some

grid generation failures were encountered due to how OpenVSP closes the trailing edge of the wing/airfoil geometries (it always forces a sharp trailing edge). In some cases the sharpness had to be removed to ensure successful grid generation. 


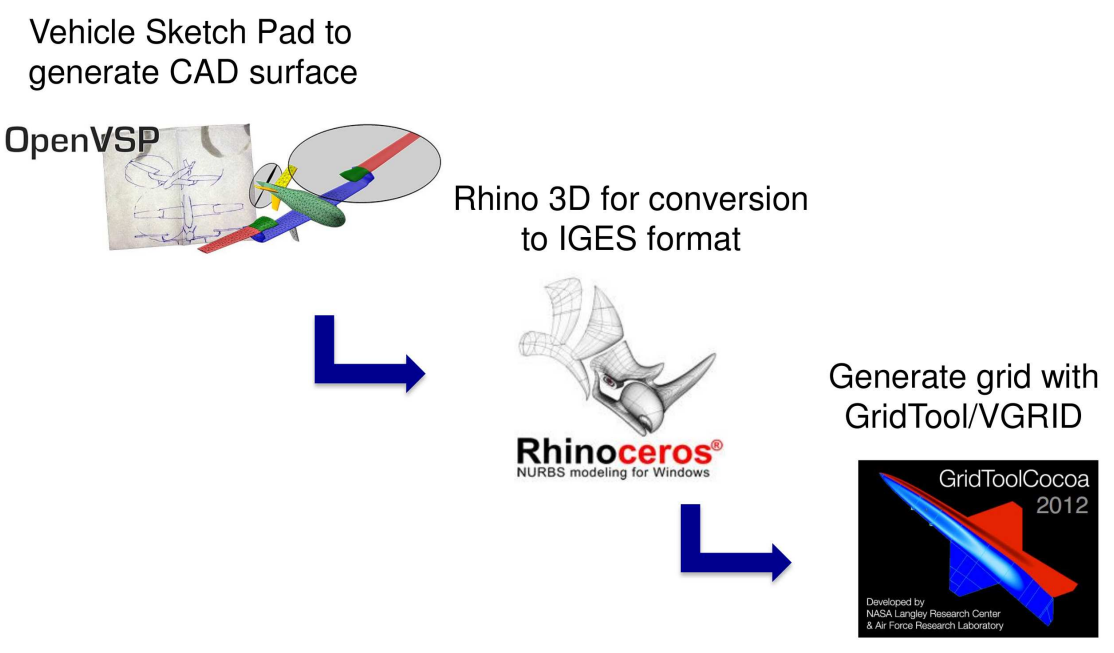

Figure 2: Process of geometry generation to grid generation

\section{B. Grid Generation}

Grid generation parameters were generalized such that, between different geometries, parameters such as source placement and viscous spacing had minimal required changes. This meant that from initial geometry generation to a completed grid would require only a matter of hours. Establishing this commonality and routine for grid generation enabled the generation of adequate grids for many configurations in a short time span. An example placement of sources for a simple tapered wing is shown in Figure 3. A series of line sources are utilized, in the spanwise direction of each wing at differing chord-wise locations. Anisotropic stretching [20] as high as 10:1 was used near the root of the wing, transitioning to isotropic cells near the wing tips. For viscous tetrahedral layer generation, the height of the first layer $\left(\Delta z_{1}\right)$ is Reynolds number dependent. A viscous layers spacing tool called USGUTIL, was used to determine the height of the initial viscous layer. In order to have adequate number of cells in the viscous layers, the $y^{+}$of the first node was set to be 3 , this would ensure that the $y^{+}$of the first cell center would be less than 1 (approx. 0.75) as is required for a fully viscous Navier-Stokes solution. The values used for the grid growth parameters $(a$ and $b)$ in Eq. 1 were 0.15 and 0.02 respectively [20]. A grid sensitivity study was performed on a rectangular wing with aspect ratio of 12 to determine adequate grid sizing. It was found that a grid sizing of 5-9 million tetrahedral cells showed changes in $C_{L, \max }$ of approximately 0.02 between the grids. This method of grid generation was applied to all 3D wing geometries with the typical grids averaging between 9-12 million tetrahedral cells.

For airfoil calculations, a quasi 2D grid was generated on a constant-chord, short-span wing, between two reflection plane boundary condition patches. Figure 4 shows a completed grid for an NACA 0012 airfoil. A general goal was set to maintain very similar grid density between the $3 \mathrm{D}$ wing grids and the airfoil grids. This is necessary because the airfoil results were being used as input data into the low-order method discussed in the introduction while the 3D wing results from USM3D were being used to assess the accuracy of the low-order method (Figure 1). Therefore a separate grid sensitivity study was not performed specifically for airfoils. Typical airfoil grids were on the order of 300,000 tetrahedral cells and were generated using a nearly identical source placement as the 3D wing.

\section{Flow Solution Generation}

All solutions with the USM3D solver were computed with time-accurate Reynolds-Averaged Navier-Stokes (RANS). The limitations of RANS for modeling massively separated flows are well known. The more preferred Detached Eddy Simulation (DES) modeling will provide better physical representation of 3D separated flow, but with an order-ofmagnitude more expense. Since this investigation requires generation of many flow solutions, the initial focus is to determine if time-accurate RANS can provide sufficient engineering accuracy for capturing the salient aerodynamic characteristics of wings at stall and post-stall conditions. Furthermore, a consistent modeling is desired between the $2 \mathrm{D}$ airfoils and 3D wings.

All computations were advanced at a characteristic time step of $\Delta t^{*}=\Delta t \cdot U_{\infty} / c_{r e f}=0.02$ using a second order time-accurate scheme with three-point backward differencing and physical time stepping. The number of subiterations for each time step was set to between 10 and 15 to ensure adequate sub-iteration convergence. The Spalart- 


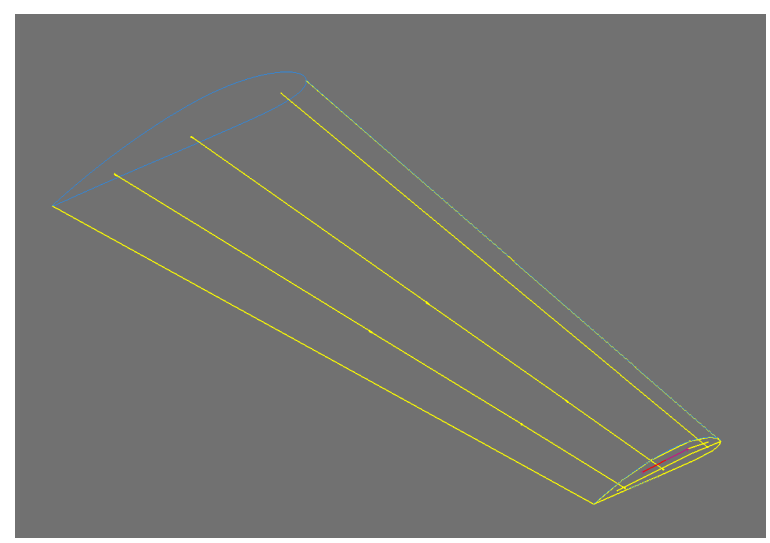

Figure 3: Screen capture of GridTool source placement on a tapered wing.

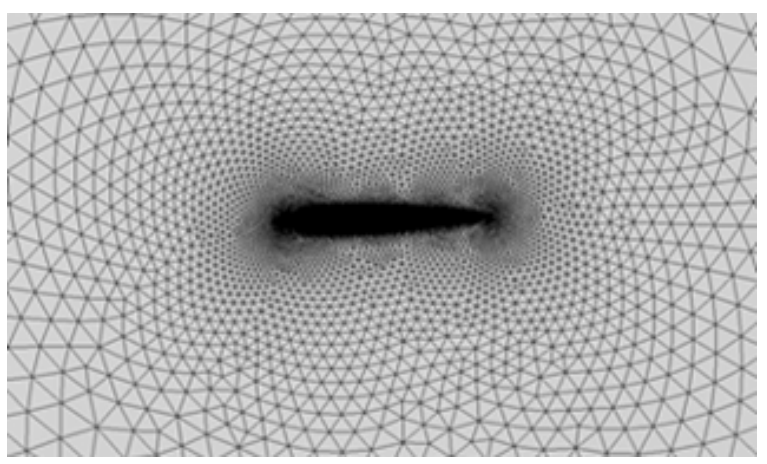

Figure 4: Screen capture of airfoil grid.

Allmaras (SA) [21] one equation turbulence model was used almost exclusively, however some simulations were performed with the two equation SST turbulence model to understand the difference in final solution quantities. The solver was run on both a NASA Langley computer cluster and the North Carolina State University High Performance Computing (NCSU HPC) cluster. Making use of USM3D's parallel computation capabilities, each grid was partitioned into 28-64 equal zones which could be loaded onto 28-64 individual processors, reducing calculation times significantly. To further increase productivity, a series of Unix scripts were developed to generate the required input files for job submission and minor post-processing of completed jobs.

\section{Solution Convergence}

Convergence of the solutions was monitored by generating convergence plots such as that seen in the Figure 5. Unix scripts were used to compile all of the convergence information contained in the USM3D output files into a Tecplot format. Each plot showed the logarithm of the residual over each iteration and the changes in the aerodynamic coefficients. The criteria for a fully converged solution was for each plot to show a leveling off of the quantities under consideration. These plots allowed for rapid determination of whether any given solution had reached a converged state (Figure 5a) or if the solution had attained an unsteady solution shown by oscillatory convergence (Figure 5b).

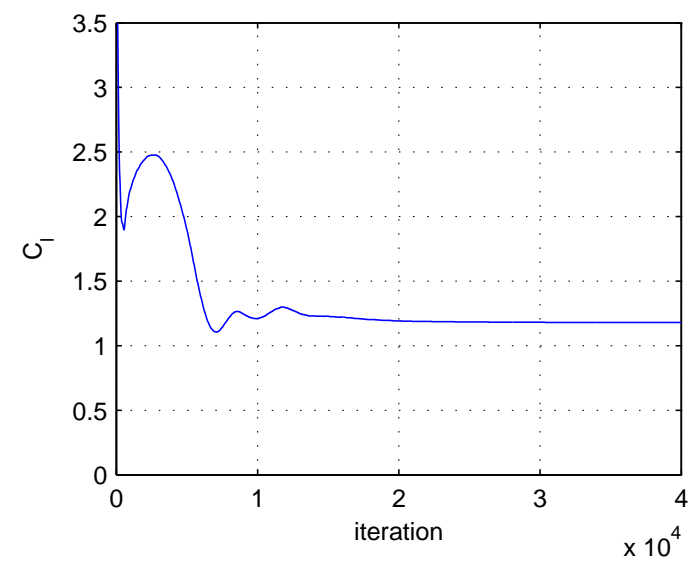

a) Smooth convergence, $\alpha=30 \mathrm{deg}$.

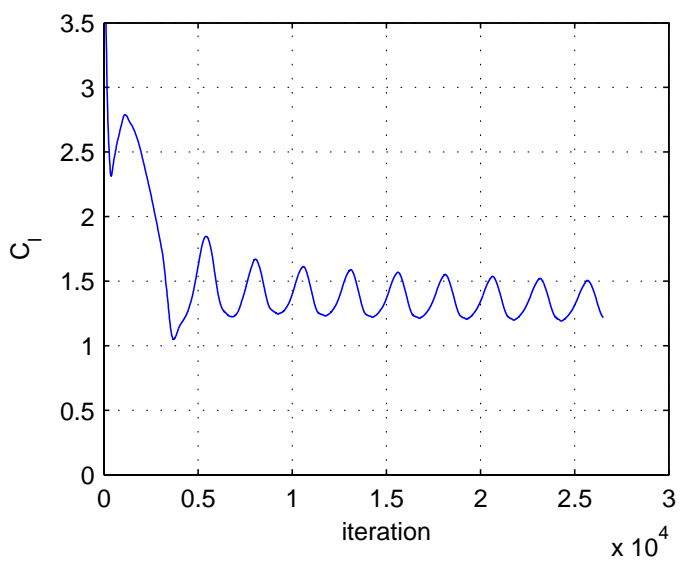

b) Oscillatory convergence, $\alpha=48 \mathrm{deg}$.

Figure 5: Typical USM3D convergence of lift coefficient for an airfoil. NACA 4415, USM3D/SA, RE = 3 million, $M_{\infty}=0.2$. 


\section{E. Post-Processing}

After solution convergence was verified, the data is processed so that total forces and moments, the spanwise distribution of forces and moments, and flow visualization may be studied. As was previously mentioned, in some cases an oscillatory solution develops rather than single steady-state values for the forces and moments. This has only been observed for 2D airfoil solutions at very high angles of attack. To handle such cases, a method had to be developed in order to address these oscillations.

\section{Forces and moments acting on the entire wing/configuration}

The first outputs of interest are the total force and moment coefficients acting on a wing/configuration. A script was used to extract the body-axis force and moment coefficients [ $C_{X} C_{Y} C_{Z} C_{M x} C_{M y} C_{M z}$ ], defined parallel and perpendicular to the body coordinate system, and stability-axis coefficients $\left[C_{L} C_{D}\right]$, defined parallel and perpendicular to the free-stream velocity. Figure 6 shows an example of lift coefficient results for a 2D airfoil and a 3D wing which used the same airfoil cross section.

\section{Span-wise distribution of forces on a surface}

The other output of interest is the span-wise distribution of force coefficients, particularly the span-wise lift coefficient. The PREDISC utility [22], was used for extracting this information. PREDISC simultaneously loads the grid files containing the surface grid and a converted TetrUSS solution file containing only surface data. Data extraction planes can be arbitrarily defined (see Figure 7) and PREDISC will output surface pressure and skin

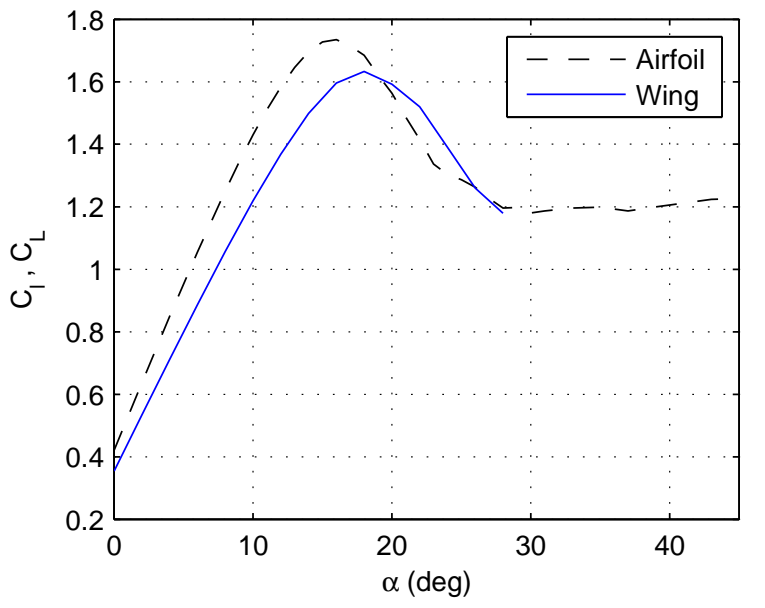

Figure 6: Comparison of lift coefficients for 2D airfoil (NACA 4415) and $\mathrm{AR}=12$ rectangular wing at $\mathrm{RE}=3$ million. friction coefficients, $C_{p}$ and $C_{f}$ respectively, along the surface discretized according to a fine mesh of $x / c, y / c$ locations. The surface pressure and skin friction coefficients are integrated to approximate body-axis force coefficients. An example lift coefficient distribution obtained by integrating the $C_{p}$ and $C_{f}$ values at each extraction plane is shown in Figure 7.
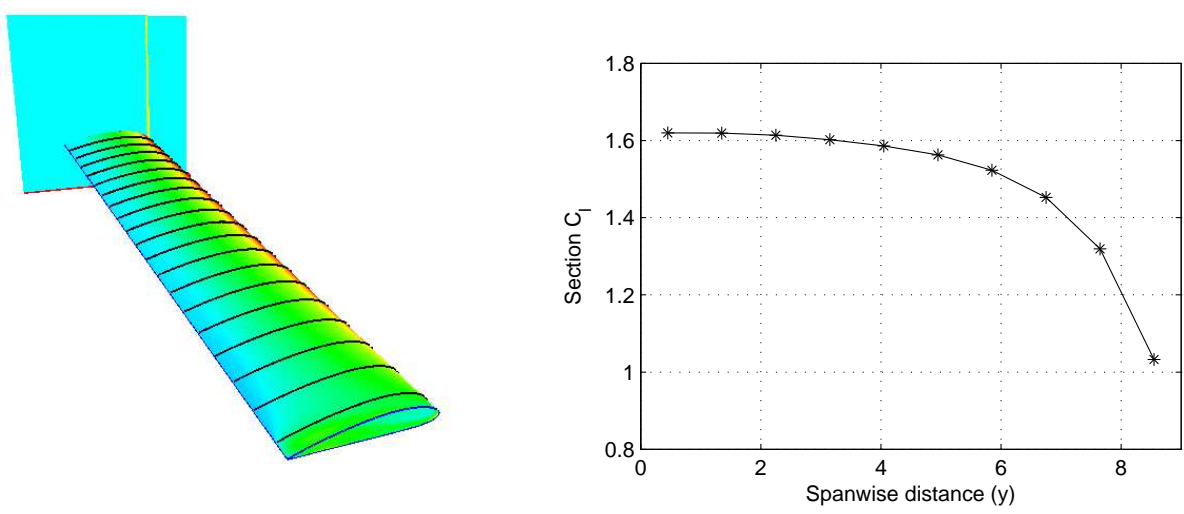

Figure 7: Screen shot of PREDISC code (left) showing defined data extraction planes and a plot of the extracted spanwise $C_{l}$ distribution (right) on a rectangular wing $\mathrm{AR}=12$. 


\section{Results}

The results shown in this section represent the current level of development of the CFD database. The results from analysis of 2D airfoil CFD solutions for cambered, symmetric and thin airfoils will be presented along with 3D wing solutions with rectangular, tapered and swept planforms.

\section{A. 2D Airfoil Results}

Three different airfoils have been studied and added to the CFD aerodynamic database to date. Additional airfoils will be added as needed for further development of the database and as required for validation of the low-order post-stall method discussed previously. The airfoils chosen exhibit different stall and post-stall behavior and offer insight on how certain airfoil geometries will tend to behave at high angles of attack. Results for a symmetric airfoil (NACA 0012), a cambered airfoil (NACA 4415) and a very thin airfoil (NACA 63006) are shown in this section. The geometries of the airfoils are shown in Figure 8.

One interesting phenomenon that was encountered while developing the airfoil database, was the tendency for the airfoil solutions to exhibit oscillatory behavior in the force and moment convergence histories at angles of attack of approximately 40 degrees and above. The cause of these oscillations was determined using flow visualization which revealed periodic vortex shedding from the upper surface of the airfoil. A process to average the oscillatory behavior and determine peak to peak amplitudes was established. A post-processing MATLAB script was developed to read all of the force and moment

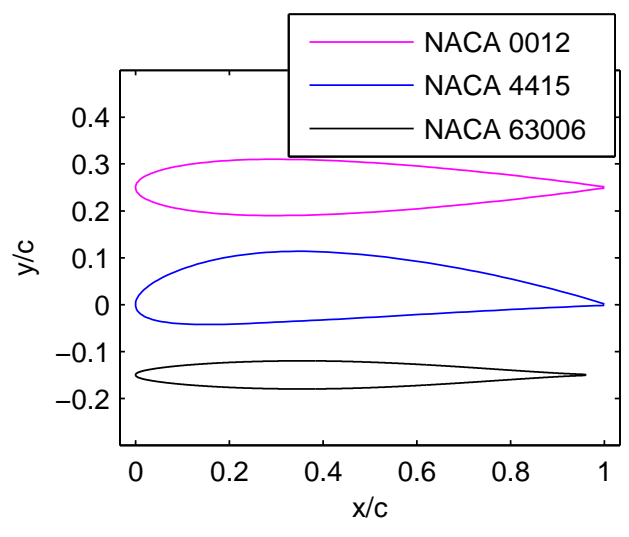

Figure 8: Comparision of airfoil geometry for the three cases studied.

history files for an airfoil and detect the oscillatory behavior. For any angle of attack that displayed this behavior, the script identified two complete cycles at the end of the convergence history and determined the mean value along with the peak to peak amplitude. The plots in Figure 9 illustrate the approach used for the processing of the raw CFD data with this code.

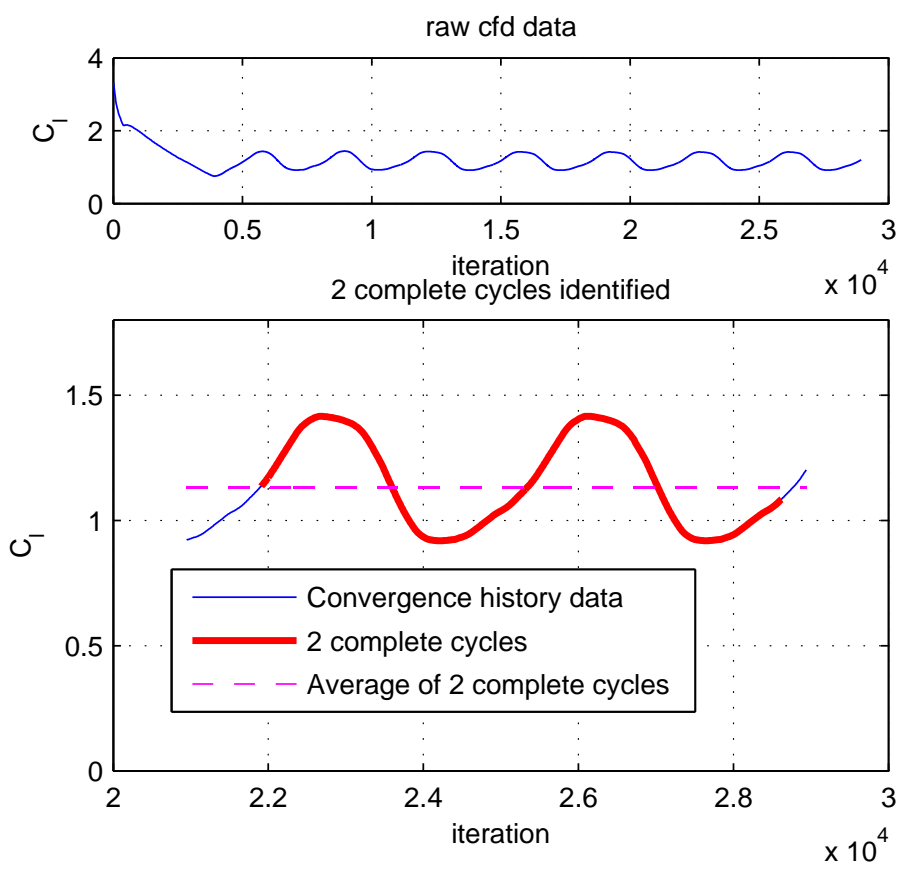

Figure 9: Illustration of approach used for averaging oscillator airfoil CFD convergence history. 


\section{Reynolds Number Effects Through Post-Stall}

The general effects of Reynolds number on the aerodynamic quantities, specifically $C_{l, \max }$, are known and have been observed with the current work as well. However, it is important to extend this to the post-stall region. Figure 10 shows a comparison of the lift curves for the NACA 4415 airfoil at three different Reynolds numbers (3, 6 and 10 million). The increased maximum lift coefficient with increased Reynolds number is expected. In the post stall region between angle of attack of 40 and 70 degrees, an additional effect of the Reynolds number is seen. The region falls directly where the oscillatory solutions develop; the values shown in Figure 10 are the averaged values from any oscillating data. After this recovery region, the solutions tend to follow a similar path out to 90 degrees.

\section{Sharp vs. Blunt Trailing Edge Geometries}

It has been noted by Hoerner [23], that the trailing edge shape of an airfoil has a distinguishable effect on the $C_{l}$ vs. $\alpha$ curve. When comparing an airfoil with a sharp trailing edge with the same airfoil but with a blunt trailing edge, it is found the the maximum lift coefficient is seen to be higher for the blunt trailing edge airfoil. The plot in Figure 11 displays results for an NACA 4415 airfoil with both a sharp and blunt trailing edge at a Reynolds number of 3 million. The blunt TE geometry was generated by removing the final one percent of the chord of the sharp trailing edge geometry, thus no other alterations to the geometry are present. The expected trend is seen with the blunt trailing edge case having a higher maximum lift coefficient. It is interesting to see that this effect seems to continue all the way past stall and through to approximately $\alpha=70$ degrees, after which the lift curves coincide. The flow mechanism that allows for this all the way through post stall is not readily apparent from the CFD at this time, but warrants further investigation.

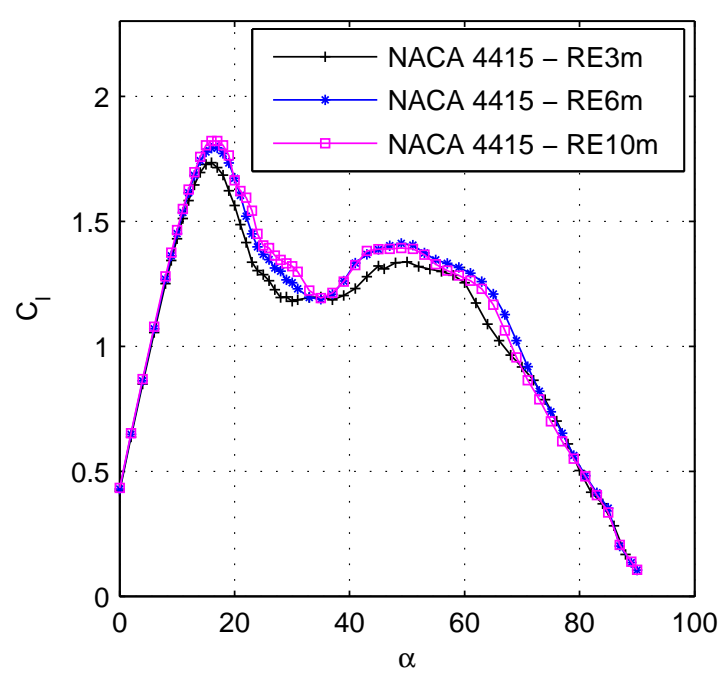

Figure 10: Effect of Reynolds number on lift coefficient for an NACA 4415 airfoil. USM3D/SA, $M_{\infty}=$ 0.2 .

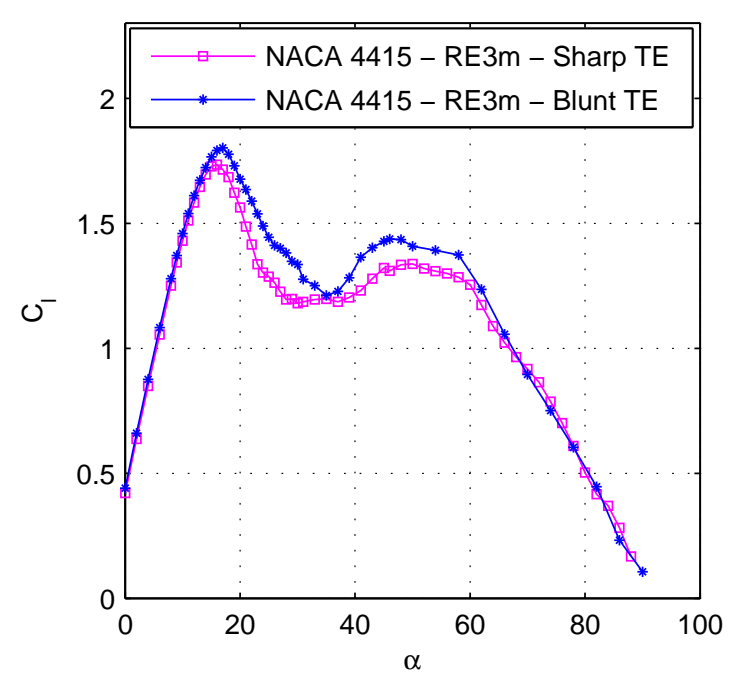

Figure 11: Effects of trailing-edge sharpness for an NACA 4415 airfoil. USM3D/SA, $\operatorname{Re}=3$ million, $M_{\infty}$ $=0.2$.

\section{Comparison of Post-Stall Characteristics of Three Airfoil Geometries}

Airfoils that exhibit different characteristics in terms of maximum lift coefficient and stall behavior were analyzed for addition to the post-stall database. In Figure 12, lift curves for three airfoils are shown from 0 to 90 degrees angle of attack. A cambered airfoil (NACA 4415), a symmetric airfoil (NACA 0012) and a very thin airfoil (NACA 63006) are compared in the figure. The NACA 4415 and NACA 0012 both exhibit trailing edge stall behavior. That is, flow separation begins at the trailing edge and progresses towards the leading edge as the angle of attack increases. This can be seen in the lift curves as both the airfoils have a relatively "gentle" stall. It is interesting to note that although the NACA 4415 airfoil has a higher $C_{l, \max }$ as compared to the NACA 0012, the two airfoils have very similar maximum recovery lift coefficients at approximately 50 degrees angle of attack. The NACA 63006 produced a much 
more unusual lift curve. This airfoil is categorized as having "thin airfoil" stall characteristics. Due to the presence of a severe adverse pressure gradient around the leading edge at even low angles of attack, the flow over the upper surface completely separates. This sudden onset of flow separation can been seen by the sudden leveling of the lift coefficient at around 10 degrees. After this initial "stall", the airfoil recovers past the initial stall lift coefficient and reaches nearly the same maximum recovery $C_{l}$ at $\alpha=50$ degrees as the NACA 4415 and NACA 0012 . The differences seen between these three airfoils in the 40 to 60 degree range can mainly be attributed to thickness, camber and leading-edge radius effects.

An enlarged plot of the NACA63006 in the region of incipient stall is shown in Figure 13 with comparison to experimental data obtained from Abbott and von Doenhoff [1] and also noted by Hoerner [23]. It should be noted that since the CFD solutions were fully turbulent (no transition model was used) no evidence or effects of a laminar separation bubble near the leading edge were modeled, a phenomenon noted by Leishman and in other studies of similar airfoils [24].

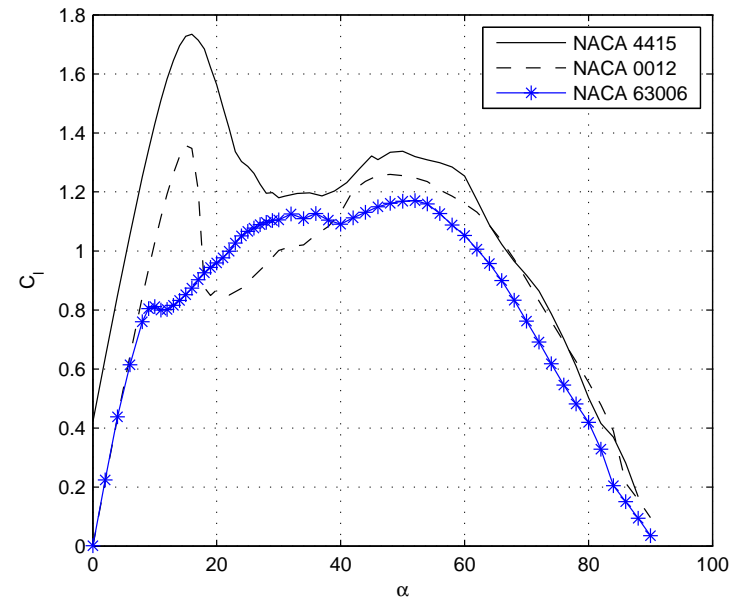

Figure 12: Comparison of $C_{l}$ vs. $\alpha$ for three airfoil types. USM3D/SA, $\mathrm{Re}=3$ million, $M_{\infty}=0.2$

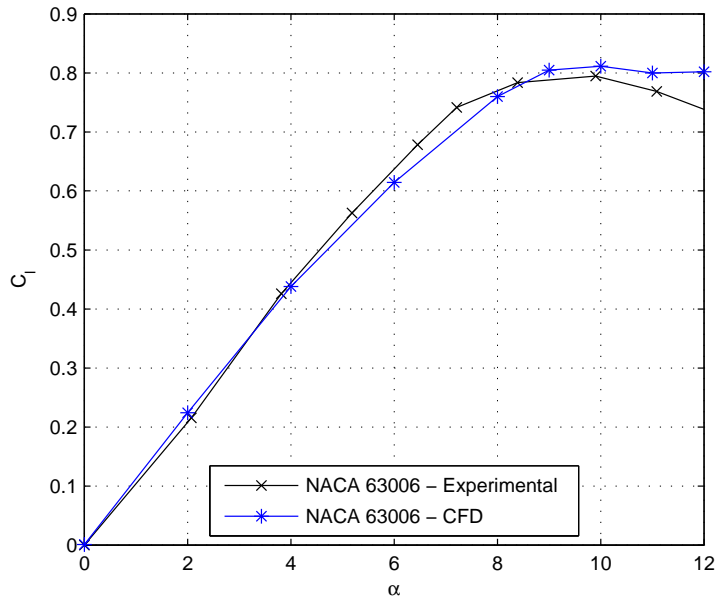

Figure 13: Comparison of $C_{l}$ vs. $\alpha$ from CFD and experiment for the NACA 63006 thin airfoil.

Figures 14 and 15 show Mach number contour plots along with surface $C_{p}$ distributions for the NACA 4415 and NACA 63006 airfoils at different stages along their respective lift curves. The NACA 4415 flow visualization in Fig. 14 at $\alpha=17$ degrees. $\left(C_{l, \max }\right)$ shows the presence of trailing edge stall propagating forward along the chord. This is also evident in the $C_{p}$ distribution. As the angle of attack is extended above stall and into post-stall, a large wake region is seen to develop accompanied by a loss of much of the suction peak. At $\alpha=50 \mathrm{deg}$. a snapshot of the Mach contours and $C_{p}$ distribution show the unsteady behavior that exists. At $\alpha=88$ degrees the solution shows massively separated flow typical of bluff bodies. A small suction peak is still generated around the leading edge resulting in a small amount of lift generation. 

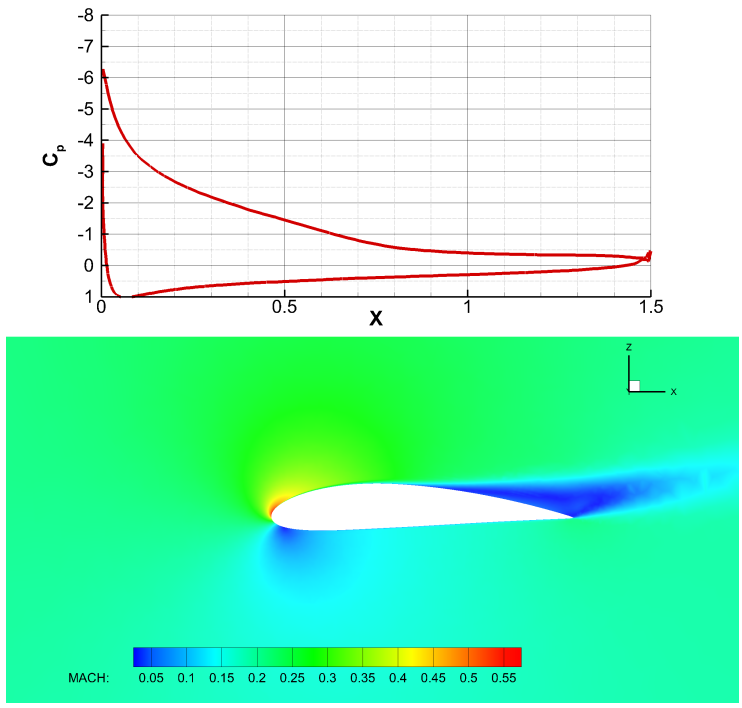

a) $\alpha=17 \mathrm{deg}$.
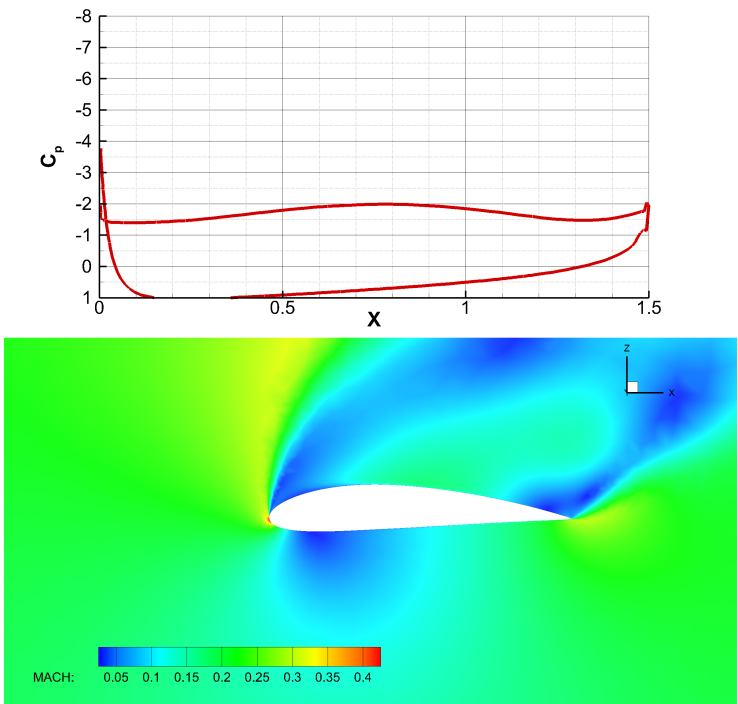

c) $\alpha=\mathbf{5 0}$ deg.
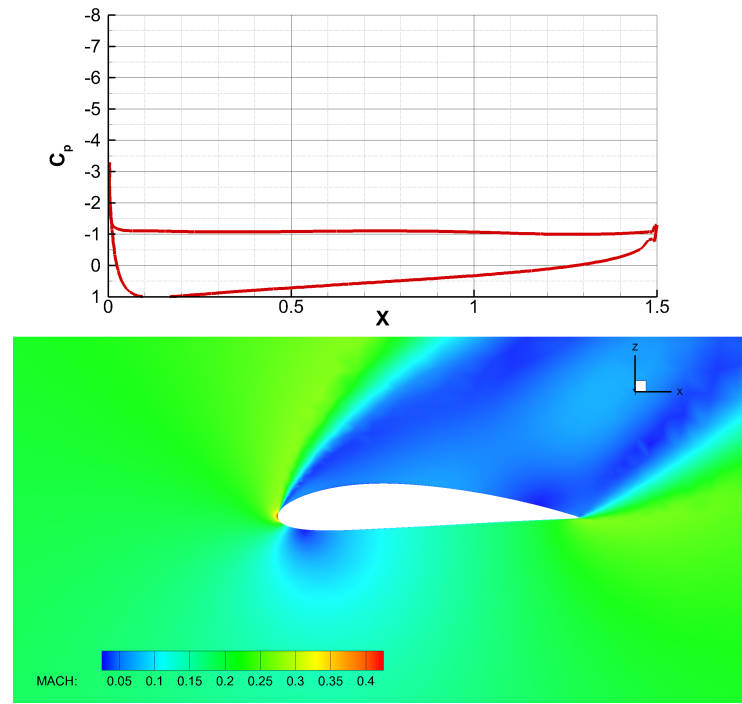

b) $\alpha=39 \mathrm{deg}$.
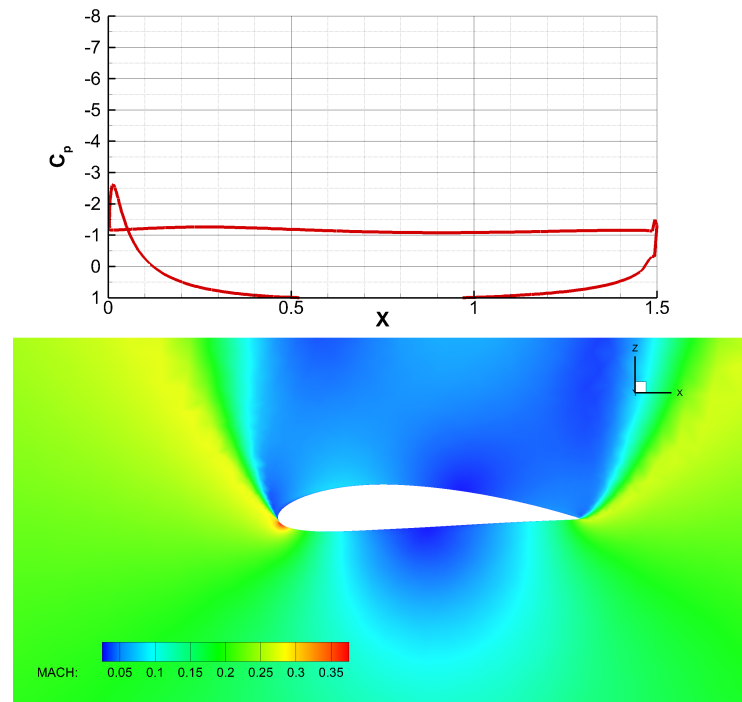

d) $\alpha=88 \mathrm{deg}$.

Figure 14: Mach contours and $C_{p}$ distribution for a NACA 4415 airfoil. USM3D/SA, $\operatorname{Re}=3$ million, $M_{\infty}=0.2$.

The flow visualization of the NACA 63006 CFD solutions in Fig. 15 provides an interesting view of thin-airfoil stall behavior. It can be seen from Figure 15 that, at $\alpha=6$ degrees, there is a significant suction peak followed by a steep adverse gradient. The leading edge at this angle of attack shows a small area of separated flow. Looking back at Figure 13, a slight change in the slope of the lift curve can be identified in this region. At 10 degrees angle of attack, the flow on the upper surface is completely separated; this corresponds with the maximum lift coefficient prior to the airfoil entering into the recovery region in post-stall. The $C_{p}$ distribution at 24 degrees angle of attack shows a larger internal area signaling an increase in the normal force generated, the majority of which still falls along the lift direction. The airfoil reaches another " $C_{l, \max }$ " at approximately 50 degrees and also shows unsteady characteristics. 

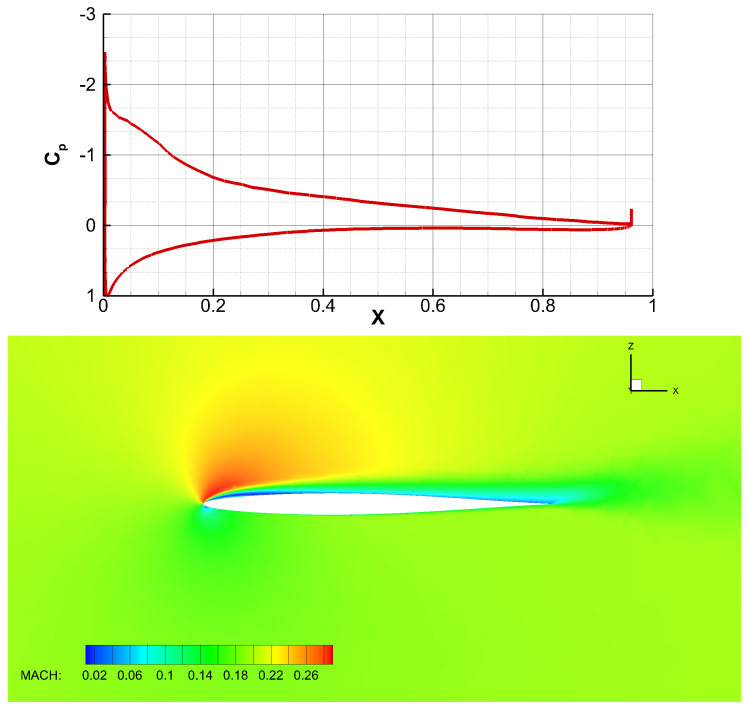

a) $\alpha=6$ deg.
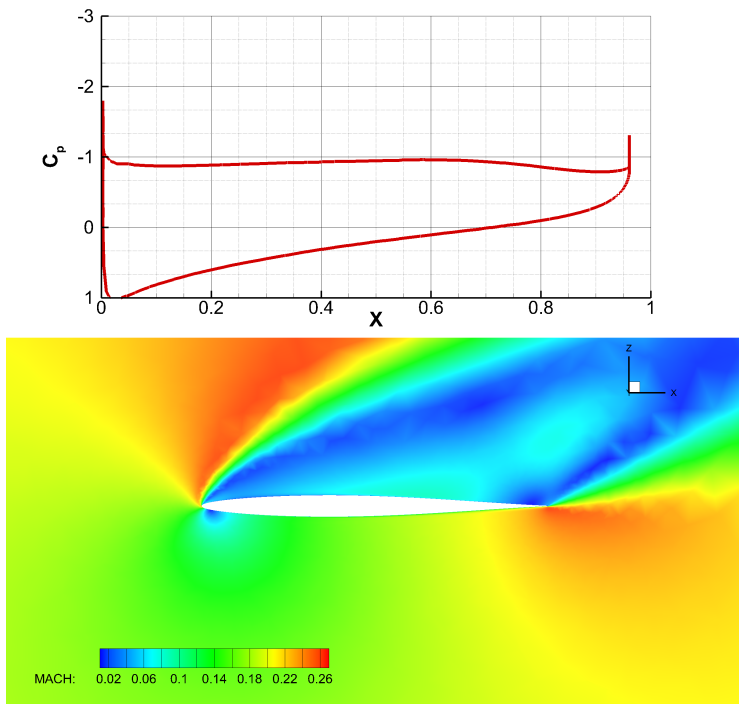

c) $\alpha=24$ deg.
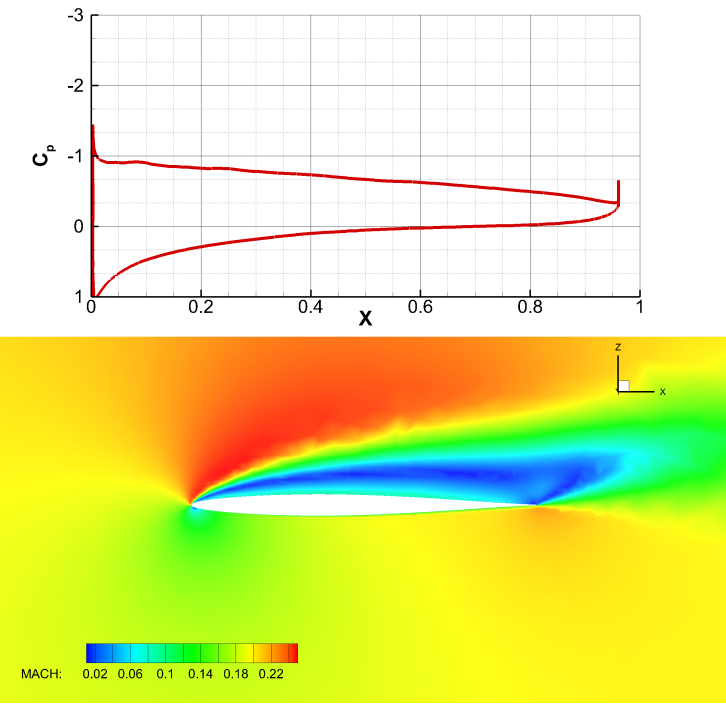

b) $\alpha=10 \mathrm{deg}$.
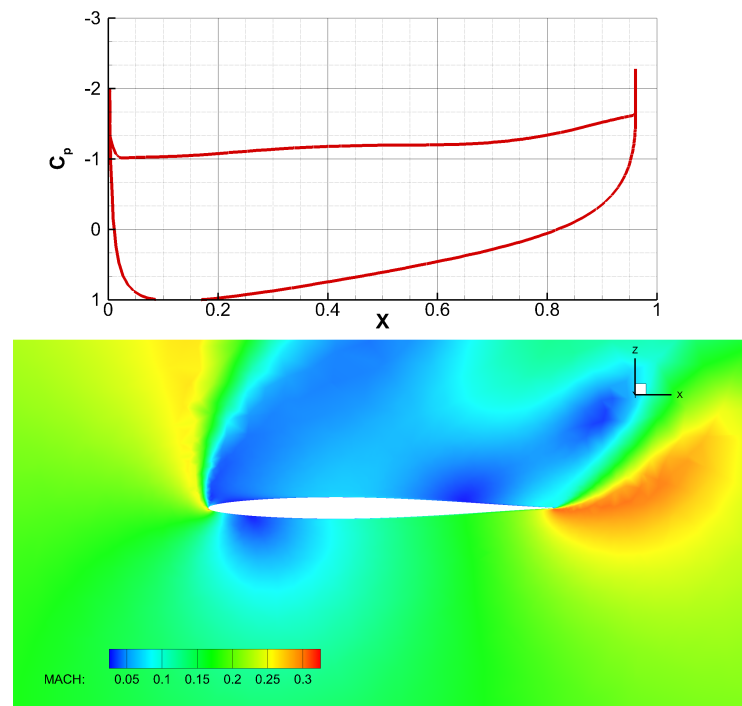

d) $\alpha=50 \mathrm{deg}$.

Figure 15: Mach contours and $C_{p}$ distribution on a NACA 63006 airfoil. USM3D/SA, $\operatorname{Re}=3$ million, $M_{\infty}=0.2$.

\section{B. 3D Wing Results}

Results of various 3D wing geometries are presented in the following subsection. The plots in Figures 16 and 17 display the lift curves for multiple wing planform geometries. Only a subset of the geometries have been run completely to 90 degrees due to the extensive run time of the solutions and the limited availability of computing nodes. The effects of both taper and sweep have been studied. The database will eventually include wing geometries that have a combination of both sweep and taper, similar to civilian transport aircraft. This data will be of interest to continuing efforts aimed at improving safety of transport aircraft. Detailed spanwise load distributions and surface streamline flow visualizations are presented in this paper for three wings of $\mathrm{AR}=12$ with rectangular, tapered and swept planforms.

\section{Rectangular Wing}

The results presented are for a rectangular wing with an aspect ratio of 12 and an NACA 4415 airfoil cross section. The solutions for this case were produced for a Reynolds number of 3 million based on the chord and a Mach number of 0.2 . The plots in Figure 18 show a snapshot of the spanwise $C_{l}$ distributions calculated from the time-accurate 


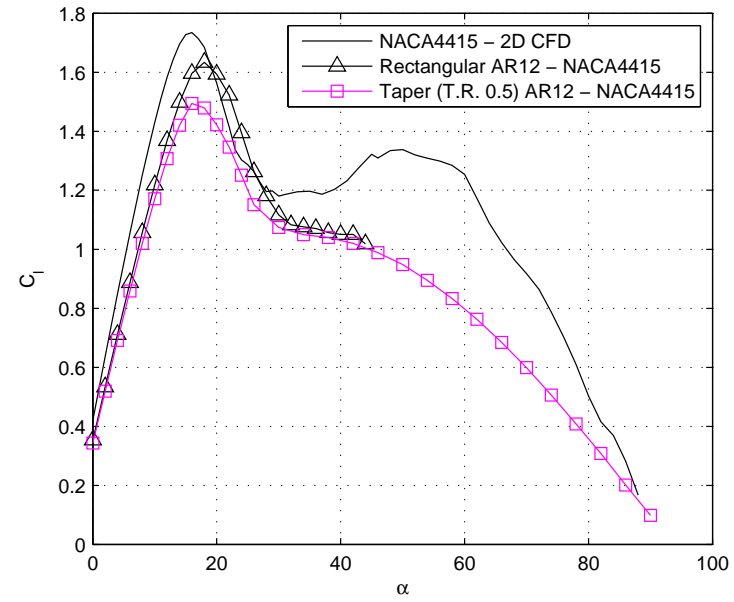

Figure 16: Effect of taper on unswept wings: $C_{L}$ vs. $\alpha$. $\mathrm{USM} 3 \mathrm{D} / \mathrm{SA}, \mathrm{Re}=3$ million, $M_{\infty}=0.2$.

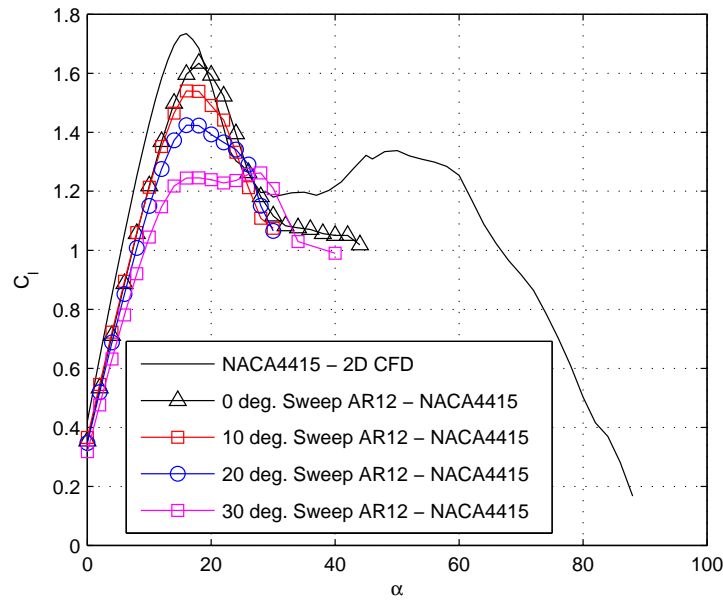

Figure 17: Effect of sweep on constant-chord wings: $C_{L}$ vs. $\alpha$. USM3D/SA, $\operatorname{Re}=3$ million, $M_{\infty}=0.2$

CFD solutions for angles of attack near stall and into post-stall. It is seen that at an angle of attack of 18 degrees, a sawtooth pattern in the $C_{l}$ distribution is present. The extent of this sawtooth pattern seems to grow at 22 degrees and 28 degrees. Correlating these load distributions with flow visualization at the same angles of attack enlightened the reason for the sawtooth patterns. Through the use of surface streamlines it can be seen in Figure 19 that as the angle of attack increases, reversed flow is seen aft of the separation line and shows the presences of multiple stall cells forming along the semi-span of the wing. This causes certain sections along the wing to have more attached flow than others, generating the oscillations in the the local lift coefficients going from the root to the tip. This stall cell formation eventually dissipates as the flow over the upper surface becomes fully separated and the region of reversed flow reaches the leading edge of the wing as can be seen at 28 degrees. The streamlines in Figure 19 seem to suggest that even in high angle of attack situations the surface flow is still relatively in the chord-wise direction for the majority of the semi-span. There are some variations near the borders of stall cells and near the wing tip as would be expected due to the influence of the tip vortex.

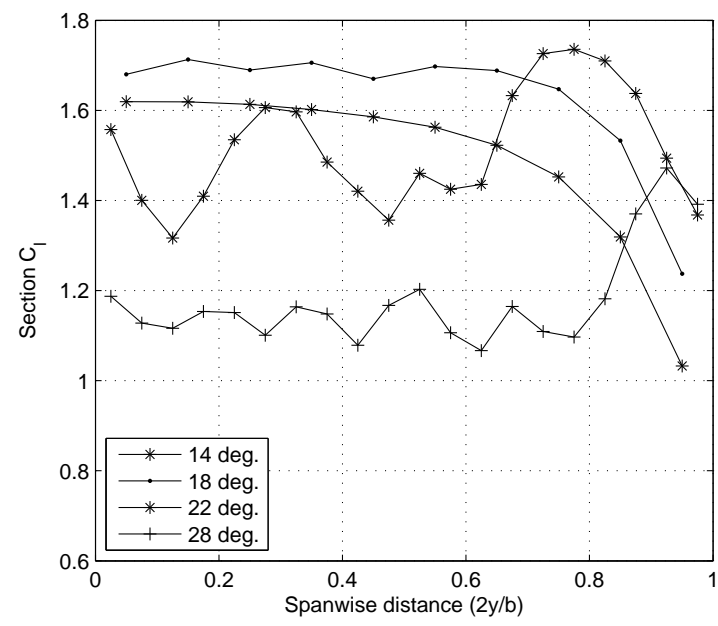

a) Local $C_{l}$ distribution at various angles of attack

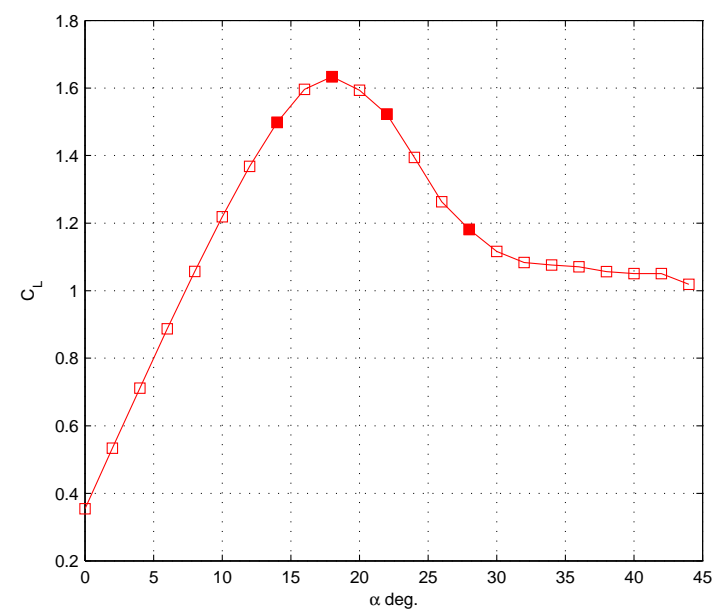

b) Corresponding points on $C_{L}$ vs. $\alpha$ curve

Figure 18: Comparison of local $C_{l}$ distribution at various angles of attack for a rectangular wing AR $=12$. USM3D/SA, $\operatorname{Re}=3$ million, $M_{\infty}=0.2$. 


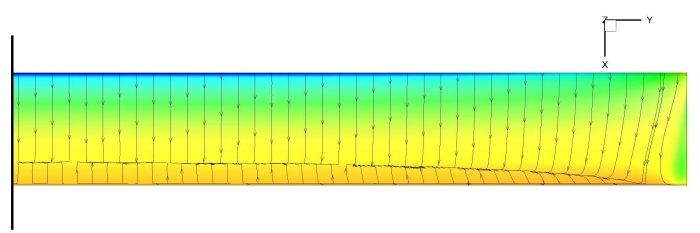

CP: $\begin{array}{lllllllllll} & -4 & -3.5 & -3 & -2.5 & -2 & -1.5 & -1 & -0.5 & 0 & 0.5\end{array}$

a) $\alpha=14 \mathrm{deg}$.

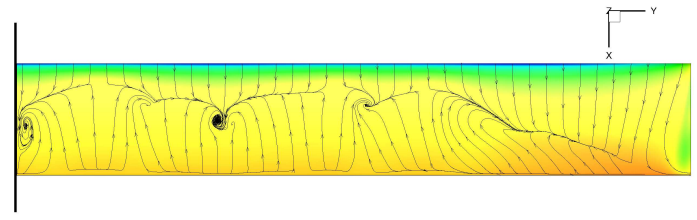

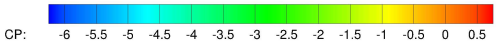

c) $\alpha=22$ deg.

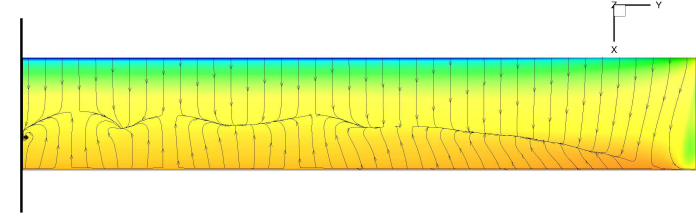

$\mathrm{CP}$

b) $\alpha=18 \mathrm{deg}$.

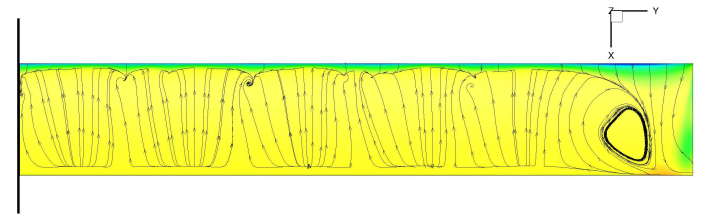

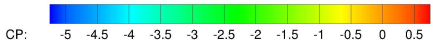

d) $\alpha=28 \mathrm{deg}$.

Figure 19: $C_{p}$ contours and surface streamlines on a semi-span rectangular wing, $\mathrm{AR}=12$, symmetry plane indicated by black line. USM3D/SA, $\mathrm{Re}=3$ million, $M_{\infty}=0.2$.

\section{Tapered Wing}

Results for a tapered wing with a taper ratio of 0.5 and aspect ratio of 12 are presented in Figures 20 and 21. This wing also has the same NACA 4415 airfoil cross section and the solutions were generated for a Mach number of 0.2 and Reynolds number of 3 million based on the mean aerodynamic chord. The $C_{l}$ distributions in Figure 20 show that the highest $C_{l}$ is seen near the middle of the semi-span at 14 degrees angle of attack.

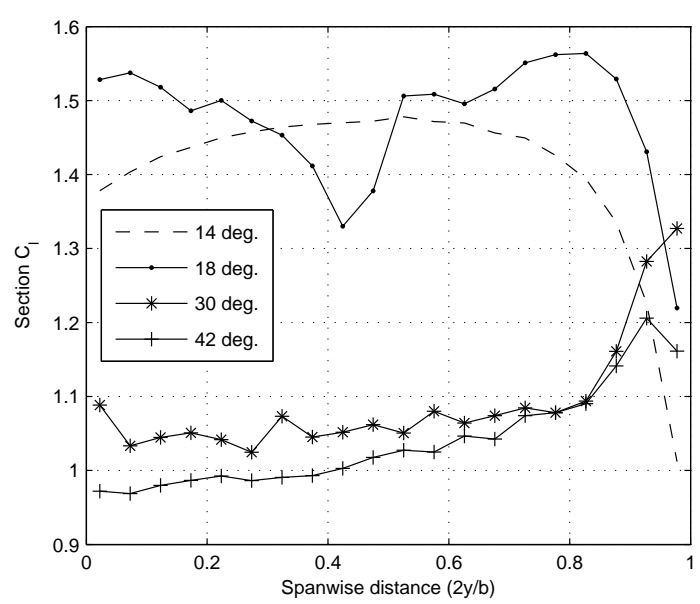

a) Local $C_{l}$ distribution at various angles of attack

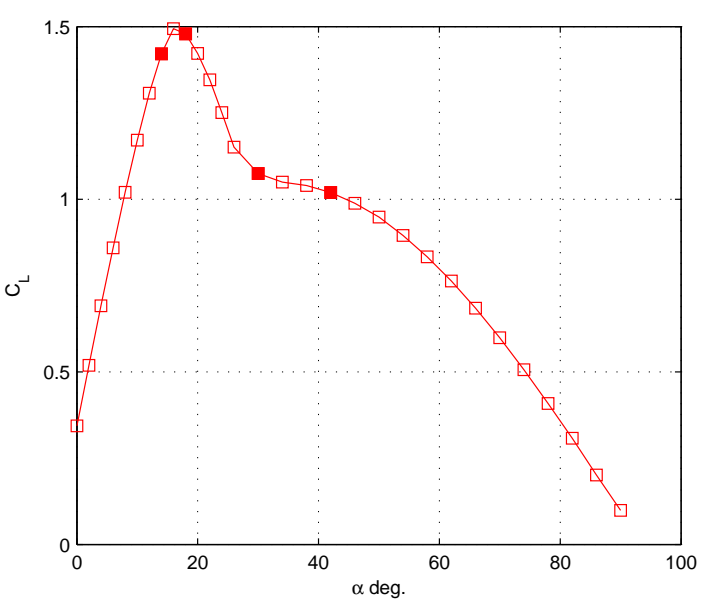

b) Corresponding points on $C_{L}$ vs. $\alpha$ curve

Figure 20: Comparison of local $C_{l}$ distribution at varying angles of attack for a tapered wing, $\lambda=0.5$ and $\mathrm{AR}=12$. $\mathrm{USM} 3 \mathrm{D} / \mathrm{SA}, \mathrm{Re}=3$ million, $M_{\infty}=0.2$.

Such increases in local span $C_{l}$ can be an indicator of impending stall in that region. As anticipated, a stall cell develops near this high $C_{l}$ area of the semi-span at 18 degrees, which is denoted by the severe drop in the local lift coefficients. Looking at the surface streamlines in Figure 21 shows the existence of the stall cell as predicted by CFD. Similar to the rectangular case, these stall cells disappear once the angle of attack is high enough that the flow on the upper surface 
is entirely separated. Chord-wise reversed flow is still seen along the majority of the semi-span at highly separated conditions.

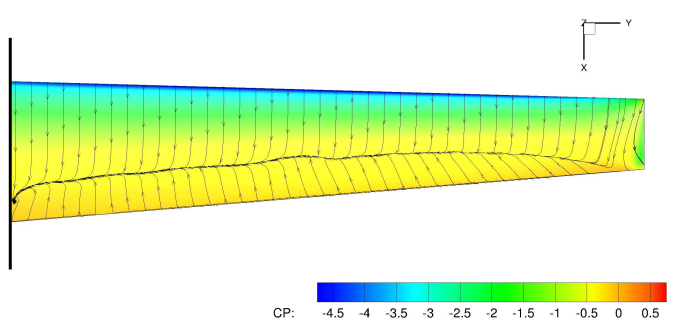

a) $\alpha=14$ deg.

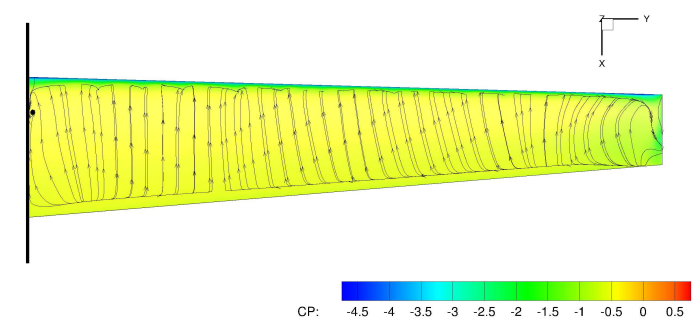

c) $\alpha=30 \mathrm{deg}$.

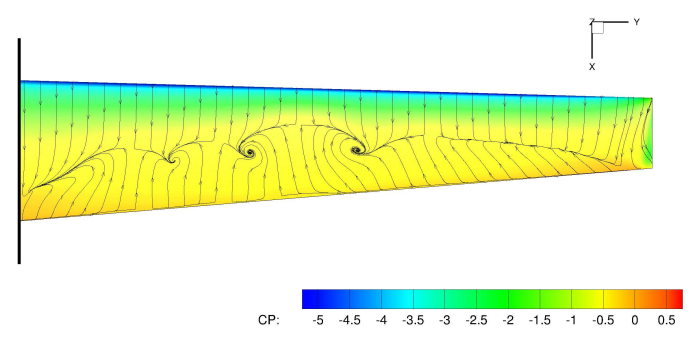

b) $\alpha=18 \mathrm{deg}$.

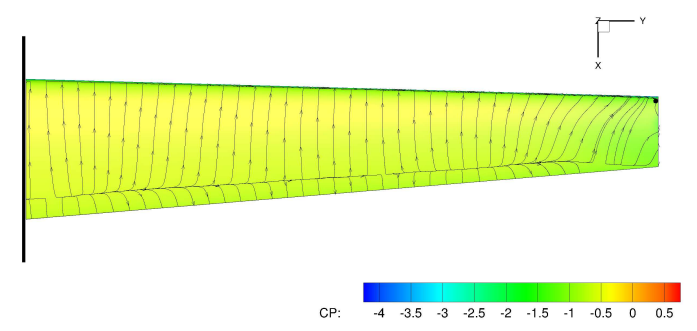

d) $\alpha=42 \mathrm{deg}$.

Figure 21: $C_{p}$ contours and surface streamlines on a tapered wing, $\lambda=0.5, \mathrm{AR}=12$, symmetry plane indicated by black line. USM3D/SA, $\mathrm{Re}=3$ million, $M_{\infty}=0.2$.

\section{30 Degree Swept Wing}

Results are presented for a swept wing case with 30 degrees of sweep, an aspect ratio of 12 and an NACA 4415 cross section parallel to the plane of symmetry. The solutions were generated at a Mach number of 0.2 and Reynolds number of 3 million. Spanwise $C_{l}$ distributions are shown in Figure 22. Stall progression from near the tip of the wing towards the inboard sections of the wing is evident and expected. As the angle of attack increases to 30 degrees the inboard local lift coefficients (calculated here based on a streamwise section, not chord-wise) are well above observed maximum lift coefficient seen for the NACA 4415 2D airfoil CFD solutions (approx 1.75). This phenomenon however has been observed in past studies of swept wings. Hunton and James [25] as well as Harper and Maki [10] note this same behavior, which is most pronounced at inboard sections near the root, but can occur along most of the semispan. They describe this as an effect of a "natural boundary-layer control" that delays stall on the inboard section of a swept wing. It should also be noted that the percent increase in the local sectional $C_{l, \max }$ goes up with the sweep angle. Evidence of this delayed stall near the root of the 30 degree swept wing can be seen in Figure 23. The inboard section does not show significant flow separation even at 30 degrees angle of attack, while the rest of the wing is fully separated. 


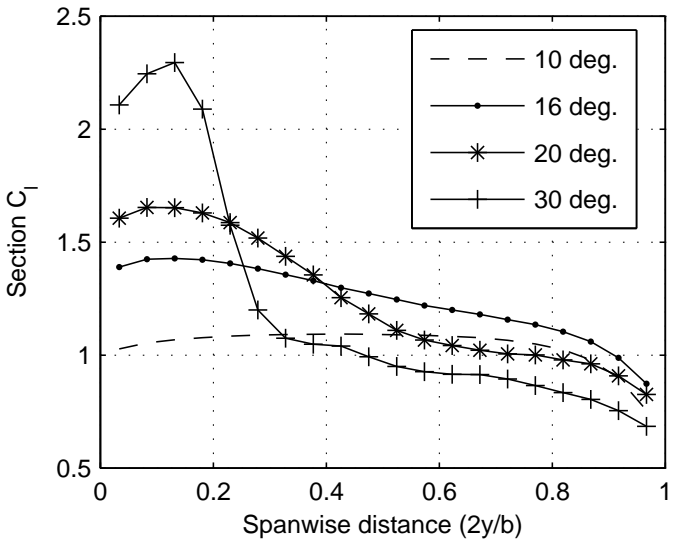

a) Local $C_{l}$ distribution at various angles of attack

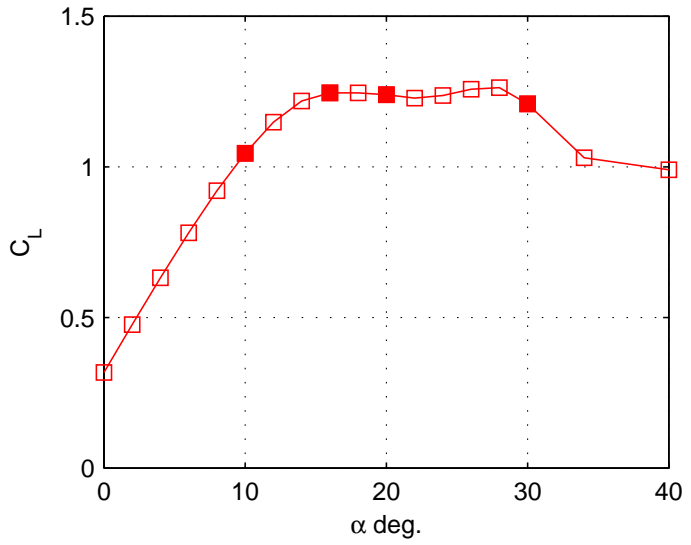

b) Corresponding points on $C_{L}$ vs. $\alpha$ curve

Figure 22: Comparison of local $C_{l}$ distribution at various angles of attack on a swept wing, $\Lambda=30$ deg., $\mathrm{AR}=12$. $\mathrm{USM} 3 \mathrm{D} / \mathrm{SA}, \mathrm{Re}=3$ million, $M_{\infty}=0.2$.

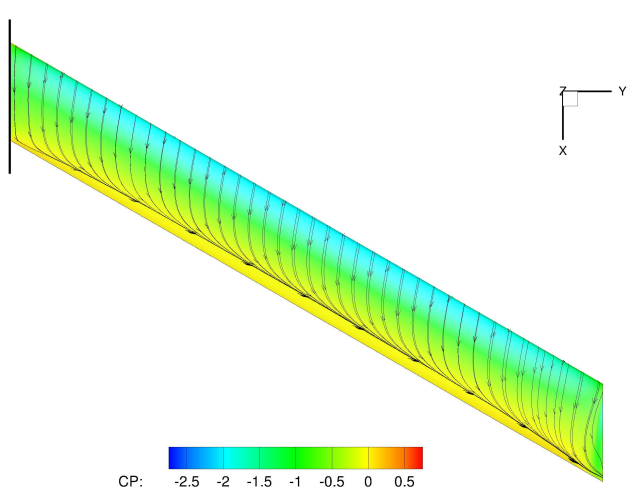

a) $\alpha=10$ deg.

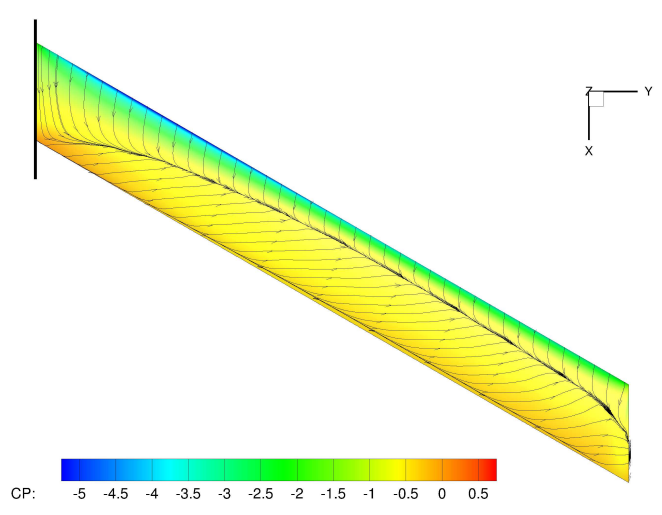

c) $\alpha=20 \mathrm{deg}$.

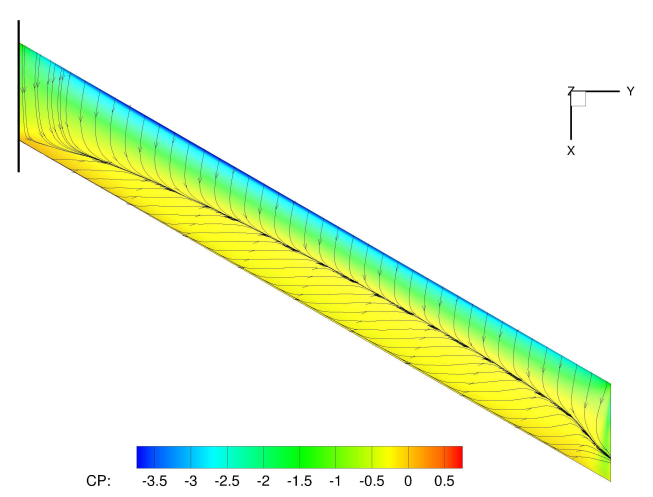

b) $\alpha=16 \mathrm{deg}$.

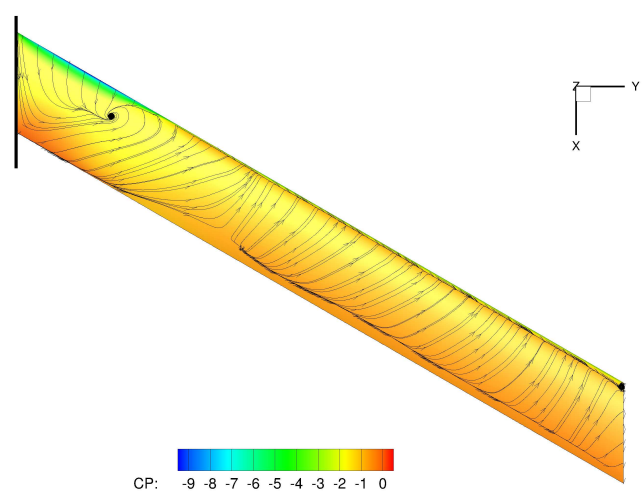

d) $\alpha=30 \mathrm{deg}$.

Figure 23: $C_{p}$ contours and surface streamlines on a swept wing, $\Lambda=30$ deg., $\mathrm{AR}=12$, symmetry plane indicated by black line. USM3D/SA, $\operatorname{Re}=3$ million, $M_{\infty}=0.2$.

\section{Conclusions}

This paper presents on-going research related to the development of an aerodynamic database of airfoils and wings through post-stall angles of attack. Such data has potential for use in modeling post-stall flight dynamics of fixedwing and rotary-wing aircraft, and for prediction of wind turbine performance. Except for a few sources, however, 
there is a dearth of post-stall aerodynamic data from experimental or computational studies. One objective of the current work is in filling this gap in the knowledge. Further motivation behind developing this database is that it is expected to be of use in the validation and refinement of a low-order post-stall aerodynamics prediction method being developed for wings and aircraft configurations. The current approach to the development of this database is to use the NASA TetrUSS CFD package to analyze the geometries using Reynolds Averaged Navier Stokes equations. The CFD analyses enables flow solutions to be generated for various geometries (both 2D and 3D) in a more rapid fashion than would be possible with experimental work, besides providing detailed spanwise lift coefficients, and separation patterns that are not easily available from experimental studies.

In this paper, results are first presented for three airfoils that exhibit different stall and post-stall behaviors. The results for these and other airfoils will be used as input data for the low-order post-stall prediction method for finite wings. Another objective in obtaining these results is that studying the post-stall behavior of these airfoils may lead to the development of a rapid method of generating airfoil force and moment curves from 0 to 90 degrees angle of attack using a combination of results from XFOIL and other simplified models such as the flat plate theory for very high angles of attack. Next the paper presents results for finite wings to illustrate the effects of taper ratio and sweep angles on stall and post-stall behavior. The results for the rectangular and tapered unswept wings show that the flow along wing sections is nominally two-dimensional even at post-stall conditions. The nominally two-dimensional flow provides confidence in the use of sectional data in modeling post-stall aerodynamics of finite wings. However, there is noticeable variation in the shape of the upper-surface flow separation line, resulting in saw tooth oscillations in the spanwise lift-coefficient distributions. It is not clear if these saw tooth oscillations have any correspondence with similar oscillations seen in the results predicted by the low-order post-stall method.

In contrast to the results for unswept wings, the results for swept wings are seen to be highly three dimensional, as expected. At and beyond stall, there is significant spanwise flow on the upper surface. As a result of this spanwise flow (resulting from spanwise pressure gradients) and the higher lift coefficients on the outboard portions of the wing in pre-stall conditions, the outboard portions of the swept wings stall first while the root portion maintains lift coefficients much higher than the maximum lift coefficient in two-dimensional flow. The consequences of such behavior for aircraft stall characteristics, namely tip stall with associated rolling moment and pitch-up moment at stall, are well known. In the context of the low-order modeling, the significant three-dimensional flow on swept wings at and beyond stall poses serious stumbling blocks. It remains to be seen how these effects can be captured correctly and efficiently in a low-order aerodynamic model that can be used in real-time flight dynamics simulation. The benefit of such CFD studies, however, is that the detailed results do provide the very type of sought-after information for developing phenomenological augmentation of low-order approaches even when the flow is not entirely twodimensional. In follow-on work, continued expansion of the database will progress with the addition of more airfoil and wing geometries. Studies of wing-tail geometries and effects of angular velocities are also planned.

\section{Acknowledgments}

The CFD portion of the effort was supported by a grant from the NASA Langley Research Center under the Vehicle Systems Safety Technologies project. We thank technical monitor Gautam Shah for the support and collaboration. Justin Petrilli gratefully acknowledges the guidance and mentoring from Neal Frink of NASA Langley in the use

of the TetrUSS CFD software. Ryan Paul gratefully acknowledges support from the National Science Foundation Graduate Research Fellowship Program.

\section{References}

[1] Abbott, I. H. and von Doenhoff, A. E., Theory of Wing Sections, Dover, New York, 1959.

[2] Althaus, D. and Wortmann, F. X., Stuttgarter Profilkatalog I, Friedr. Vieweg \& Sohn, Braunschweig, 1981.

[3] Selig, M. S., Guglielmo, J. J., Broeren, A. P., and Giguère, P., Summary of Low-Speed Airfoil Data, Vol. 1, SoarTech Publications, Virginia Beach, Virginia, 1995.

[4] Selig, M. S., Lyon, C. A., Giguère, P., Ninham, C. N., and Guglielmo, J. J., Summary of Low-Speed Airfoil Data, Vol. 2, SoarTech Publications, Virginia Beach, Virginia, 1996.

[5] Lyon, C. A., Broeren, A. P., Giguère, P., Gopalarathnam, A., and Selig, M. S., Summary of Low-Speed Airfoil Data, Vol. 3 , SoarTech Publications, Virginia Beach, Virginia, 1998.

[6] Drela, M., "XFOIL: An Analysis and Design System for Low Reynolds Number Airfoils," Low Reynolds Number Aerodynamics, edited by T. J. Mueller, Vol. 54 of Lecture Notes in Engineering, Springer-Verlag, New York, June 1989, pp. 1-12.

[7] Critzos, C. C., Heyson, H. H., and Jr., R. W. B., "Aerodynamic Characteristics of NACA 0012 Airfoil Section at Angles of Attack From $0^{\circ}$ to $180^{\circ}, "$ NACA Technical Note 3361, January 1955.

[8] Tangler, J. L., “Insight into Wing Turbine Stall and Post-stall Aerodynamics," Wind Engineering, Vol. 7, 2004, pp. $247-260$. 
[9] Lindenburg, C., "Aerodynamic Airfoil Coefficients at Large Angles of Attack," IEA Symposium Paper ECN-RX-01-004, 2001.

[10] Harper, C. W. and Maki, R. L., “A Review of the Stall Characteristics of Swept Wings,” NASA TN D-2373, 1964.

[11] Ostowari, C. and Naik, D., "Post Stall Studies of Untwisted Varying Aspect Ratio Blades with an NACA 4415 Airfoil Section-Part 1," Wind Engineering, Vol. 8, No. 3, 1984, pp. 176-194.

[12] Mukherjee, R. and Gopalarathnam, A., "Poststall Prediction of Multiple-Lifting-Surface Configurations Using a Decambering Approach," Journal of Aircraft, Vol. 43, No. 3, May-June 2006, pp. 660-668.

[13] Gopalarathnam, A., Paul, R., and Petrilli, J., "Aerodynamic Modeling for Real-Time Flight Dynamics Simulation (Invited)," AIAA Paper 2013-0969, January 2013.

[14] Frink, N. T., Pirzadeh, S., Parikh, P., and Pandya, M., "The NASA Tetrahedral Unstructured Software System (TetrUSS)," The Aeronautical Journal, Vol. 104, No. 1040, 2000, pp. 491-499.

[15] Pirzadeh, S., "Three-Dimensional Unstructured Grids by the Advancing Layer Method," AIAA Journal, Vol. 33, No. 1, 1996, pp. 43-49.

[16] Pirzadeh, S., "Unstructured Viscous Grid Generation by the Advancing-Layers Method,” AIAA Journal, Vol. 32, No. 8, 1994, pp. 1735-1737.

[17] Lohner, R. and Parikh, P., "Three-dimensional grid generation by the advancing front method," International Journal for Numerical Methods in Fluids, Vol. 8, No. 10, 1988, pp. 1135-1149.

[18] Frink, N. T., “Tetrahedral Unstructured Navier-Stokes Method for Turbulent Flows,” AIAA Journal, Vol. 36, No. 11, 1998, pp. 1975-1982.

[19] Fredericks, W. J., Antcliff, K. R., Costa, G., Deshpande, N., Moore, M. D., Miguel, E. A. S., and Snyder, A. N., “Aircraft Conceptual Design Using Vehicle Sketch Pad,” AIAA Paper 2010-658, 2010.

[20] Frink, N. T., Pirzadeh, S. Z., Atkins, H. L., Viken, S. A., and Morrison, J. H., "CFD Assessment of Aerodynamic Degradation of Subsonic Transport Due to Airframe Damage," AIAA Paper 2010-500, 2010.

[21] Spalart, P. and Allmaras, S., “One-Equation Turbulence Model for Aerodynamic Flows,” AIAA Paper 92-0429, 1992.

[22] Pandya, M. J., Khaled S. Abdol-Hamid, R. L. C., and Frink, N. T., "Implementation of Flow Tripping Capability in the USM3D Unstructured Flow Solver,” AIAA Journal, , No. 2006-0919, January 2006.

[23] Hoerner, S. and Borst, H., Fluid-Dynamic Lift, Hoerner Fluid Dynamics, 1985.

[24] Li, D., "Numerical Simulation of Thin Airfoil Stall By Using a Modified DES Approach," International Journal For Numerical Methods In Fluid, Vol. 54, 2007, pp. 325-332.

[25] Hunton, L. W. and James, H. A., "Use of Two-Dimensional Data In Estimating Loads on a $45^{\circ}$ Sweptback Wing with Slats and Partial-Span Flaps,” NACA TN 3040, 1953. 